\title{
Divergent Effects of Nigella Sativa Linn and Omebrazole on the Healing Of Gastric Ulcer in Adult Female Albino Rats
}

\author{
${ }^{1}$ Mohamed N. Seddek, ${ }^{2}$ Salwa M. Thabet, ${ }^{2}$ Fawkyeia A. El-Hodairy, \\ ${ }^{2}$ Shaimaa A. Haredy \\ ${ }^{1}$ Dept. Of Immunology, Faculty of Sciences At, Benha University, Egypt. \\ ${ }^{2}$ Departments of Physiology, NODCAR, Giza, Egypt.
}

\begin{abstract}
Gastric ulcer is one of the most common gastrointestinal tract diseases, and has affected on humans for centuries. Helicobacter pylori infection, use of drugs such as Nonsteroidal anti-inflammatory drugs (NSAIDs), and stress are some of the known factors that can cause gastric ulcers. NS (Nigella sativa) has been used in traditional medicine. It used for the treatment of a variety of diseases including gastrointestinal disorders. The aim of this study to evaluate the balanced between defensive and aggressive factors in the stomach and investigated the treated effects of NS ethanolic extract against Indomethacin induced gastric ulcer in rats. 48 Rats were divided at random into 6 groups 8 for each, $I^{\text {st }}$ G negative control group treated with CMC $0.5 \mathrm{ml} / \mathrm{kg} \mathrm{BWt}, 2^{\text {nd }} \mathrm{NSG}$ treated with NS $150 \mathrm{mg} / \mathrm{kg} \mathrm{BWt}, 3^{\text {rd }}$ OG treated with Omebrazole $3 \mathrm{mg} / \mathrm{kg} \mathrm{BWt}, 4^{\text {th }} I G$ Indomethacin group treated with $30 \mathrm{mg} / \mathrm{kg} \mathrm{BWt}, 5^{\text {th }} I N S G$ Indomethacin and NS, and $6^{\text {th }} I O G$ Indomethacin and Omebrazole with the same dose. These studies revealed the successful effectiveness of the alcoholic extract of $N$ sativa seeds in doses of $150 \mathrm{mg} / \mathrm{kg}$ daily for two weeks in inducing significant $(P<0.05)$ treatment against gastric ulcer compared with IG. INSG and IOG showed a significant increase of RBCs $\times 10^{6} / \mathrm{mm}^{3}$, Neutrophils $\%$, Prostaglandin $E_{2}\left(P_{G E} n g / l\right), \mathrm{NO}_{3} \mu \mathrm{mol} / \mathrm{ml}$ and Reduced Glutathione GSH. and significant decrease of WBCs, $\mathrm{HB}$, Lymphocytes \%, PH, Total Acidity, Free Acidity, $\mathrm{NO}_{2}$ and MDA. Our results suggest that NS extract possesses significant antiulcerogenic actions in gastric ulcer induced by using indomethacin (as NSAIDs) that might be related to its anti-inflammatory and antioxidant activity.
\end{abstract}

Keywords: Rats Gastric Ulcer, Nigella sativa, Omebrazole, Indomethacin.

\section{Introduction}

Gastric ulcers are a serious problem in many parts of the World. The aetiology of gastric ulcers is influenced by various factors Ulcers are worsened by inadequate dietary habits, excessive ingestion of nonsteroidal anti-inflammatory drugs (NSAIDs), stress, hereditary predisposition and infection by Helicobacter pylori (Repetto, 2002). Peptic ulcer occurs due to an imbalance between the aggressive (acid, pepsin and Helicobacter pylori) and the defensive (gastric mucus and bicarbonate secretion), prostaglandins, innate resistance of the mucosal cells factors. (Tripathi, 1999).Gastric ulceration in man is associated with reduced gastric mucosal prostaglandin $\mathrm{E} 2\left(\mathrm{PGE}_{2}\right)$ synthesis, this finding which persists despite healing by proton pump inhibitors (Pugh et al., 1989). The mechanism of ulcerogenesis in the different model has similarities to human model gastric ulcer with increased secretion of gastric acid (Kirkegaard $\boldsymbol{e t}$ al., I980), reduced acid neutralizing capacity (Leung et al., 1985), inhibition of gastric alkaline mucosal secretion in response to the increased luminal acid (Briden et al., I985), impaired gastric microcirculation (Leung et al., I985; Ikeda and Kitajima I985) and a decrease in mucus formation (Shiina et al., I985). Other changes may be of pathophysiological importance: a dose-related increase in tissue histamine and histidine decarboxylase levels (Boesby et al., I983). Gastric ulcers associated with the use of nonsteroidal anti-inflammatory drugs (NSAIDs) remain a major clinical problem. NSAIDs inhibit cyclooxygenase by reducing the intrinsic ability of the mucosa to resist injury induced by endogenous and exogenous aggressors. Indomethacin (INDO), a representative of NSAIDs family, causes gastric ulcers through various processes, including generation of reactive oxygen species, initiation of lipid peroxidation, infiltration of leukocytes, induction of apoptosis, and inhibition of prostaglandin synthesis (Bech et al., 2000). Decreased prostaglandin level impairs almost all aspects of gastroprotection and increases acid secretions which in turn, aggravate the ulcer (Miller, 1983).

Several pharmaceutical products have been employed for the treatment of gastroduodenal ulcers and peptic diseases, resulting in decreased mortality and morbidity rates. However they are not completely effective and they produce many adverse effects (Rates, 2001). Omeprazole is a proton pump inhibitor which has been widely used as an acid inhibitor agent for the treatment of disorders related to gastric acid secretion for about 15 years (Ekstrom et al., 2004). In recent years, there is growing interest in alternative therapies and the use of natural products, especially those derived from plants (Rates, 2001; Schmeda-Hirschmann and Yesilada, 2005). Plant extracts are some of the most attractive sources of new drugs and have been shown to produce 
promising results for the treatment of gastric ulcer (Alkofahi and Atta, 1999; Schmeda-Hirschmann and Yesilada, 2005). Nigella sativa Linn (N. sativa) commonly known as black seed or black cumin, is an annual herb from the botanical family of Ranunculaceae. The seeds of the plant have been used in the Southeast Asia, Middle and Far East as a natural remedy to treat many diseases, including asthma, hypertension, diabetes, hypercholesterolemia, inflammation, arthritis, tumor, gastrointestinal disturbances and gynecological disorders for over 2000 years (Ali and Blunden, 2003; El-Din et al., 2006 and Ramadan, 2007). The aims of the present study to determine the efficacy of an extract of $N$. sativa in gastric ulcer induced with indomethacin.

\section{Materials And Methods}

\section{Drugs and chemicals}

Indomethacine (INDO) is powder suspended in 0.5\% Carboxy Methyl Cellulose (CMC) for oral administration $(30 \mathrm{mg} / \mathrm{kg})$ according to Halter et al. (2001). It was purchased from Pfizer company, Nigella sativa (N.S): ethanolic extract of N.S, purchased from local market, where needs N.S and crushed as powder for extraction with ethanol alcohol (95v/v)., Omebrazole (OME): is proton pump inhibitors have widely used as acid inhibitors agent for treatment a disorder related to gastric acid secretion. It is powder purchased from Cidco company dissolved in $0.5 \% \mathrm{CMC}$ for oral administration $(3 \mathrm{mg} / \mathrm{kg}$ ) and act as reference drugs according to $\mathbf{L i} \boldsymbol{e} \boldsymbol{t}$ al. (2004).

\section{Preparation of Plant}

Seeds of $N$. sativa Linn were purchased from the local market and their identification was confirmed. The seeds were dried and crushed into coarse powder which was used for extraction with ethanol alcohol (95\% $\mathrm{v} / \mathrm{v})$ using Soxhlet apparatus. The extract was evaporated under vacuum. The extractive value $(\% \mathrm{w} / \mathrm{w})$ of the alcoholic dry extract was $4.25 \%$. N.S constituents were analyzed by gas chromatography (GLC) for glycosides, flavonoids, sterols, saponins, terpenoids, alkaloids, tannins, phenolic acids, gums and mucilage using standard procedures of analysis (Evans, 2002 and Harborne, 2007).

\section{Experimental Animals}

In performing the present work, adult female albino rats Sprague Dawley weighing $150 \pm 20 \mathrm{~g}$ were used. Rats were brought from laboratory animal breeding of National Organization of Drug Control and Research (NODCAR) rats were housed under control condition for adaptation one week and fed with standard basal diet formulated in accordance with composition authorized by Association of Official Analytical chemists (1988), which consists of about $78.5 \%$ carbohydrate (inclusive of $50 \%$ crude cellulose fiber), $15.2 \%$ protein, $3.2 \%$ lipids, $2.1 \%$ salt mixture and $1 \%$ Multivitamins.

The rats were allowed free access to feeding and drinking ad libitum. They were placed in cages of adequate size each comprising 8 animals allowing free spontaneous motility. They were kept through the period of the experiment under properly controlled environmental conditions in the animal house with respect to ambient temperature (22-250C) and 12 hours dark and 12 hours light period (Adeniyi et al.,2006 and Bahuguna Yogendra et al., 2008).

\section{Experimental Design}

The aim of the present study was to determine the role of N.S seed extract in comparing with OME as reference drug in treatment of gastric ulcer in female adult rats after two weeks. Forty eight rats were fasted over night prior to the experiment in mesh-bottomed cages to minimize coprophagia but allowed free access to water except for the last hour before the experiment then food withheld $2 \mathrm{~h}$ for releasing gastric enzymes, then Pyloric ligation was carried out in each animal before indomethacin administration and ulcer induction to collect gastric juice under light ether anesthesia. Rats were injected orally with a single oral dose of $30 \mathrm{mg} / \mathrm{kg}$ of indomethacin, and After $6 \mathrm{hr}$ later, rats were divided to 6 groups for treatment of induced ulcer as follow: $1^{\text {st }} \mathrm{G}$ negative control group treated with CMC $0.5 \mathrm{ml} / \mathrm{kg} \mathrm{BWt}, 2^{\text {nd }} \mathrm{NSG}$ treated with NS $150 \mathrm{mg} / \mathrm{kg} \mathrm{BWt}, 3^{\text {rd }}$ OG treated with Omebrazole $3 \mathrm{mg} / \mathrm{kg} \mathrm{BWt}, 4^{\text {th }}$ IG Indomethacin group treated with $30 \mathrm{mg} / \mathrm{kg} \mathrm{BWt}, 5^{\text {th }}$ INSG Indomethacin and NS, and $6^{\text {th }}$ IOG Indomethacin and Omebrazole with the same dose. Rats were treated with the same drugs and doses for two weeks, after that rats were killed and stomach tissues were removed. The stomach was incised along the greater curvature and observed for ulcers (Bhatnagar et al., 2005; Muralidhran and Srikanth. $\boldsymbol{e t}$ al., 2011).

\section{Analysis Of Gastric Juice}

The gastric contents was drained and centrifuged at 3000-4.500 rpm for $10 \mathrm{~min}$. The gastric volume and $\mathrm{pH}$ were measured by $\mathrm{pH}$ meter (Moore, 1968). Free and total acidity were calculated by multiplying gastric juice volume by the measured free and total acid concentrations, respectively (Hara et al., 1991 and Feldman, 1998). 


\section{Biochemical analysis}

Serum Malondialdehyde (MDA) level was measured by the method of Karatep (2004) by HPLC. (1978). Nitric oxide (NO) content was determined by HPLC method of Papadoyannis et al., (1999), The thiols of reduced glutathione were detected by HPLC using the method of Jayatillke and Shaw (1993). Prostaglandin E2 (PGE2) assay was performed with PGE2 enzyme immunoassay kit. The supernatant was used for determination of prostaglandin E2 by using an EIA kit according to supplier's instructions (Sigma-Aldrich). At the end of experimental periods, rats were scarified. Blood was collected and hebarinized blood was used for hematological analysis experiment and measurement different hematological parameter as $\mathrm{Hb} \%$, RBCs and WBCs total count and differential count Schalm et al., (1975).

\section{Statistical Analysis}

Statistical analysis of the obtained data was performed using the general linear model (GLM) produced by Statistical Analysis Systems Institute (SAS, 1989). Significant differences among means were evaluated using Duncan's Multiple Range Test of SAS (1989).

The following linear model was applied: $Y \mathrm{ijk}=\mu+\alpha \mathrm{i}+\xi \mathrm{ij}$

Yij $=$ Observation measured

$\mathrm{M}=$ Over all mean

$\alpha \mathrm{i}=$ Effect of treatment .

$\xi \mathrm{ijk}=$ Experimental error assumed to be randomly distributed $\left(\sigma^{2}=0\right)$.

\section{RESULTS AND DISCUSSION}

Table (1): Antiulcerative Effects of Nigella sativa ( $\mathrm{mg} / \mathrm{kg} \mathrm{B.W}$ ) and other antiulcer drugs Omeprazole (mg/kg B.W) on blood WBCs x $10^{3} / \mathrm{ml}$, RBCs x $10^{6} / \mathrm{mm}^{3}$, Neutrophils\%, Lymphocytes\% and $\mathrm{Hb}$ g/dl against indomethacine induced gastric ulceration in Rats .

\begin{tabular}{|c|c|c|c|c|c|c|}
\hline & \multicolumn{6}{|l|}{ Parameters } \\
\hline Interval & Groups & WBCs $\times 10^{3} / \mathrm{ml}$ & RBCs $\times 10^{6} / \mathrm{mm}^{3}$ & Neutrophils \% & Lymphocytes \% & $\mathrm{Hb}$ g/dl \\
\hline \multirow{6}{*}{$\begin{array}{l}\text { After } 2 \\
\text { weeks of } \\
\text { Treatment }\end{array}$} & CMC & $5.56 \pm 0.24$ & $5.26 \pm 0.21$ & $35.21 \pm 1.76$ & $52.43 \pm 1.95$ & $12.38 \pm 0.46$ \\
\hline & OME & $4.52 \pm 0.16$ & $5.12 \pm 0.22$ & $37.66 \pm 2.11$ & $49.89 \pm 2.11$ & $12.50 \pm 0.46$ \\
\hline & NS & $4.91 \pm 0.19$ & $4.99 \pm 0.22$ & $35.40 \pm 2.51$ & $52.34 \pm 2.61$ & $12.63 \pm 0.50$ \\
\hline & INDO & $6.92 \pm 0.13^{\mathrm{a}}$ & $4.49 \pm 0.22^{\mathrm{a}}$ & $29.54 \pm 1.91^{\mathrm{a}}$ & $58.15 \pm 1.91^{\mathrm{a}}$ & $10.29 \pm 0.45^{\mathrm{a}}$ \\
\hline & INDO+OME & $5.68 \pm 0.34^{b}$ & $5.36 \pm 0.23^{b}$ & $35.89 \pm 1.36^{b}$ & $51.79 \pm 1.28^{\text {ab }}$ & $12.37 \pm 0.54^{b}$ \\
\hline & INDO+NS & $6.21 \pm 0.35^{\mathrm{ab}}$ & $5.23 \pm 0.29^{b}$ & $34.18 \pm 1.47^{b}$ & $51.90 \pm 1.57^{\text {ab }}$ & $13.11 \pm 0.58^{b}$ \\
\hline
\end{tabular}

- Data represents the means \pm SEM.

- a significantly different from control CMC group at $\mathrm{P}<0.05$

- $\quad$ b significantly different from INDO group against (INDO+OME and INDO+NS) at $\mathrm{P}<0.05$.

Data presented in Table (1) recorded the effect of NS and Omeprazole on serum WBCs, RBCs, Neutrophils\%, Lymphocytes\% and $\mathrm{Hb}$ g/dl against indomethacine induced gastric ulceration in Rats.

INDO produce gastric ulcer with significantly increase in total serum WBCs, Lymphocytes\%, however decrease in RBCs, Neutrophils\%, and $\mathrm{Hb}$ g/dl $(\mathrm{P}<0.05)$ as compared with control and there are no difference between two +ve control groups (NS and OME) against--ve control (CMC). On the other hand after treatment for two weeks with OME and NS as compared with INDO showed a significant increase in RBCS, neutrophil and $\mathrm{Hb}$ but they induced a significant decrease in total leukocytes ,lymphocyte.

The use of nonsteroidal anti-inflammatory drugs (NSAIDs) is considered to be the major risk factor in gastric ulcers and may produce loss of blood causing hemorrhagic anemia from gastrointestinal tract (Pratt, 1992). This precipitated low $\mathrm{Hb}$ concentration and $\mathrm{RBC}$ count which causing low capacity to carry oxygen with the resultant anoxia cyanosis and respiratory acidosis which in turn caused the death of the rats within a short period of time (Makinde, 1991). Also there is increase in the total WBC following hemorrhage this according to (Bush 1991). This increase in total WBCs count may be due to the increased hemopoitic activity as a result of the hemolysis of RBCs So This result is compatible with Gilman et al (1985) where indomethacin inhibits the motility of polymorphonuclear leukocytes.

As far the neutrophils there was a relative decrease in this parameter which might have been due to stress leading to demargination in circulation (Bush 1991). There was a relative decrease of neutrophil in blood stream and increase of neutrophil infiltration into ulcerated gastric tissue. Fujita et al. (1998) observed that an increase in neutrophil infiltration into ulcerated gastric tissue delayed the healing of gastric ulcers in rats this according to Shimizu et al. (2000). INDO would extensively damage the gastric mucosa leading to increased neutrophil infiltration into the gastric mucosa. Oxygen-free radicals derived from infiltrated neutrophils in ulcerated gastric tissues have inhibitory effect on gastric ulcers healing in rats (Suzuki et al., 1998 and Su et al., 2002). Also neutrophils mediate lipid peroxidation through the production of superoxide anions. In addition 
neutrophils are a major source of inflammatory mediators and can release potent reactive oxygen species such as superoxide, hydrogen peroxide and myeloperoxidase derived oxidants (Zimmerman et al., 1997).

It also need to be stressed that there was increasing in lymphocytes following administration of INDO to the rats showed lymphocytosis and monocytosis as a result of severe stress that the animals were subjected. This may be due to the production of specific or non specific antibodies against different antigens, since lymphocytes are responsible for achieving the defense mechanism in the body (Cheng and Koo, 2000).

NS might improve and ameliorate some disturbed hematological parameters of ulcerative rats (Al-Jishi et al., 2000). Aqel and Shaheen (1996) they found that low dose of N.S extract caused significant increase in $\mathrm{Hb}, \mathrm{PCV}$ and RBCs, also iron is essential for bacterial invasion to the body in which, iron is associated with iron binding protein transferring, lactoferrin, heptaglobin and feritin, hence N.S. eliminate iron from the body fluid to be conjugated with proteins. In addition Hedaya (1995) showed that NS made relaxation of circular muscles may protect the gastric mucosa and prevent hemolytic anemia and increase RBCs count and HB\% also promote WBC and neutrophils to control level which are compatible with our result. In addition NS prevent lymphocytes apoptosis (Mandor et al., 1998). In addition NS has antibiotic action and acts as immunoenhancer. This indicates that the treatment with NS affect the defense mechanism and immune response to inhibits the inflammation resulting from INDO treatment (Pal et al., 2001 and Zauoi et al., 2002).

Table (2): Effect of Nigilla sativa (mg / kg B.W) in comparing with anti ulcer drugs Omeprazole (mg/kg B.W) on gastric mucosa PH, Free acidity and Total acidity, against peptic ulcer by Indomethacin.

\begin{tabular}{|c|c|c|c|c|}
\hline & \multicolumn{4}{|l|}{ Parameters } \\
\hline Intervals & Groups & PH & Free acidity & Total acidity \\
\hline \multirow{6}{*}{$\begin{array}{l}\text { After } 2 \text { weeks of } \\
\text { Treatment }\end{array}$} & CMC & $2.80 \pm 0.13$ & $12.46 \pm 0.40 \mathrm{~d}$ & $22.14 \pm 1.15$ \\
\hline & OME & $3.11 \pm 0.21$ & $11.82 \pm 0.44$ & $19.98 \pm 0.99$ \\
\hline & NS & $3.18 \pm 0.21$ & $12.31 \pm 0.54$ & $22.27 \pm 1.08$ \\
\hline & INDO & $2.59 \pm 0.15^{a}$ & $50.01 \pm 1.03^{a}$ & $23.17 \pm 0.88^{a}$ \\
\hline & INDO+OME & $2.73 \pm 0.12^{a}$ & $29.38 \pm 0.86^{a b}$ & $24.43 \pm 1.05^{a}$ \\
\hline & INDO+NS & $3.15 \pm 0.17^{b}$ & $27.13 \pm 0.95^{\mathrm{ab}}$ & $47.69 \pm 0.99^{a b}$ \\
\hline
\end{tabular}

- Data represents the means \pm SEM.

- a significantly different from control CMC group at $\mathrm{P}<0.05$

- $\quad$ b significantly different from INDO group against (INDO+OME and INDO+NS) at $\mathrm{P}<0.05$.

Data presented in Table (2) recorded the treatment effect of NS and Omeprazole on pH, free and total acidity in gastric mucosal of female albino rats.INDO produce gastric ulcer with significantly increase in $\mathrm{pH}$, free and total acidity $(\mathrm{P}<0.05)$ as compared with control in gastric mucosal of female albino rats. On the other hand the treatment with OME and NS as compared with INDO showed a significant decrease in this parameter.

The major aggressive factor responsible for ulcers is the content of acid present in gastric juice (Grossman, 1978). When the concentration of hydrogen ions in gastric juice decreases, that reflects of high $\mathrm{pH}$ and a decrease in mucous and bicarbonate secretion (Tennkton et al., 1991). The genesis of ulcer and gastric damage is facilitated by hydrogen ions hence increase in free and total acidity (Lüllmann et al., 2000). OME is highly selective for the proton pump inhibitor and undergo catalyzed conversion into active form within the acid forming space. The active inhibitors react with $\mathrm{SH}$ (thiol) group of the proton pump, resulting in inhibition of acid formation (Nagaya, 1991; Wallace and Granger, 1996). Also OME is substituted benzimidazoles and it inhibits acid secretion by acting on the hydrogen-potassium exchanger (H+: K+-ATPase) for the apical plasma membrane of the gastric mucosa (Satoh, 1989 and Li et al., 2004).

From these results, NS showed the antiulcer action that exerted by their purified fraction thymoqunion inhibition of gastric aggressive factors i.e. acid and pepsin because ability to interfere with the indomethacininduced inflammatory effects which is in accordance with Alghamdi (2001)

Table (3): Effect of $N S$ (mg / kg B.W) in comparing with anti ulcer drugs Omeprazole ( $\mathrm{mg} / \mathrm{kg}$ B.W) on serum MDA nmol/ml, GSH nmol/ml, $\mathrm{NO}_{2} \mu \mathrm{mol} / 1, \mathrm{NO}_{3} \mu \mathrm{mol} / \mathrm{l}$ and PGE2 $\mathrm{ng} / \mathrm{l}$ against peptic ulcer by Indomethacine

\begin{tabular}{|c|c|c|c|c|c|c|}
\hline & Parameters & & & & & \\
\hline Intervals & Groups & MDA nmol/ml & GSH nmol/ml & $\mathrm{NO}_{2} \mu \mathrm{mol} / \mathrm{l}$ & $\mathrm{NO}_{3} \mu \mathrm{mol} / \mathrm{l}$ & PGE2ng/l \\
\hline \multirow{6}{*}{$\begin{array}{l}\text { After } 2 \text { weeks of } \\
\text { Treatment }\end{array}$} & CMC & $0.99 \pm 0.05$ & $85.35 \pm 4.91$ & $27.87 \pm 1.31$ & $16.66 \pm 0.90$ & $276.0 \pm 5.14$ \\
\hline & OME & $1.12 \pm 0.06$ & $91.74 \pm 5.31$ & $25.91 \pm 1.81$ & $16.29 \pm 0.77$ & $275.6 \pm 5.02$ \\
\hline & NS & $0.99 \pm 0.06$ & $89.33 \pm 4.10$ & $28.05 \pm 1.72$ & $17.04 \pm 0.71$ & $265.7 \pm 4.28$ \\
\hline & INDO & $2.79 \pm 0.05^{a}$ & $69.48 \pm 3.71^{\mathrm{a}}$ & $28.05 \pm 1.29^{a}$ & $18.38 \pm 0.73$ & $209.9 \pm 5.43$ \\
\hline & INDO+OME & $1.87 \pm 0.08^{a b}$ & $86.58 \pm 4.51^{b}$ & $32.28 \pm 1.49^{a b}$ & $17.75 \pm 0.79$ & $263.5 \pm 5.69^{b}$ \\
\hline & INDO+NS & $1.93 \pm 0.07^{a b}$ & $90.16 \pm 4.99^{b}$ & $30.35 \pm 1.62^{\mathrm{ab}}$ & $19.18 \pm 0.82$ & $244.2 \pm 4.28^{\mathrm{ab}}$ \\
\hline
\end{tabular}

- Data represents the means \pm SEM.

- a significantly different from control CMC group at $\mathrm{P}<0.05$ 
- $\quad$ b significantly different from INDO group against (INDO+OME and INDO+NS) at $\mathrm{P}<0.05$.

Data presented in Table (3) recorded the treatment effect of NS and Omeprazole on $\mathrm{PGE}_{2}$, and oxidative stress parameter $\left(\mathrm{GSH}, \mathrm{NO}_{2}, \mathrm{NO}_{3}, \mathrm{MDA}\right)$ in serum rats

INDO produce gastric ulcer with significantly increase in lipid peroxidation (MDA), however decrease in $\mathrm{GSH}, \mathrm{PGE}_{2}, \mathrm{NO}_{2}, \mathrm{NO}_{3}$ as compared with control. On the other hand after treatment for two weeks with OME and NS as compared with INDO showed an ameliorate effects in this parameters.

The ulceration induced by indomethacin is attributed mainly to various processes, including generation of oxygen species, initiation of lipid peroxidation, infiltration of leukocytes, induction of apoptosis, and inhibition of prostaglandin synthesis (Bech et al., 2000). These free radicals also damage the cellular antioxidant enzymes such as glutathione peroxidase, SOD and others, acting as the first line of cellular defense against oxidative injury which might contribute to mucosal injury (Chattopadhyay et al., 2006) and lead to aggravated tissue damage during stomach ulceration (El-Missiry et al., 2001).

The results of this study are in line with these previous data. Also Indomethacin produces damage to key biomolecules such as lipids. This was apparent from the stimulated lipid oxidation leading to increased accumulation of MDA as well as reduction in the gastric activity of GSH (Lanas et al., 2000).

Several studies have demonstrated the importance of endogenous NO in the protection of gastric mucosa (Kim and Kim, 1998; Tanaka et al., 2001 and Whittle et al., 1990). NO formed by endothelial NOS plays an important role in the modulation of gastric mucosal integrity by interacting with sensory neuropeptides and endogenous prostaglandins (Whittle $\boldsymbol{e t}$ al., 1990). A previous report has shown that NO protected against indomethacin-induced gastric ulceration through maintenance of mucosal blood flow and reduction of leukocyte-endothelial cell rolling and adherence (Calatayud $\boldsymbol{e t}$ al., 1999). In the present study, indomethacin significantly reduced gastric mucosal NO level compared to control group. These findings are in accordance with Trip and Tepperman who reported a decrease in NO biosynthesis, as a result of decreased NOS activity that was associated with an increase in the extent of damage (Tripp and Tepperman, 1995).

In addition decreased prostaglandin level impairs almost all aspects of gastroprotection and increases acid secretions which, in turn, aggravate the ulcer (Miller, 1983). Hiruma-Lima et al. (2006) demonstrated that prostaglandin, is a key molecule that stimulates the complex array of ulcer healing mechanism, gets synthesized in the mucosal cells by cyclooxygenase (COX) enzymes. Also stimulates the secretion of biocarbonate and mucus, maintains mucosal blood flow and regulates mucosal turn over and repair. Suppression of prostaglandins synthesis by indomethacin results in increase susceptibility of stomach to mucosal injury and gastric ulceration through the inhibition of the cyclooxygenase enzymes (Rainsford, 1987). particulary PGs increase mucosal blood flow, promote mucous secreation, and increase bicarbonate secreation. As shown in the present results, OM treatment significantly reverted the indomethacin-induced changes in MDA and GSH. This significant reduction in MDA levels along with significant increase in GSH level suggest decreased lipid peroxidation and antioxidant activity of OM.. Proton pump inhibitors promote healing mechanism of gastric mucosa via antisecretory mechanism of $\mathrm{PGE}_{2}$ by exerting some effects on COX expression in not only non steroidal inflammatory drugs ulcer but also in common ulcers (Bush, 1991).

NS provided a marked suppression of oxidative damage due to its excellent radical scavenging capacity; it brought MDA level closer to normal levels (Okabe et al., 1997). Thimoqunione(TQ) which the main constituents of nigella sativa and its metabolite dihydrothymoquinone have an important role in lipid peroxidation and scavenging free radicals (antioxidant properties) according to (Mansour et al., 2002). TQ can react non enzymatically with GSH, NADH and NADPH to form glutathionyl-dihydrothymoquinone, after rapid reaction with GSH, and dihydrothymoquinone after slow reaction time with NADH and NADPH, offering thus, an evidence for powerful free radical scavengers, even more than TQ it self (Khalife and Lupidi, 2007).There fore, when these metabolites are formed they can remove superoxide anions, as well as other free radicals formed, an effect that can spare the endogenous antioxidant defense molecules, GSH and SOD, and prevent lipid peroxidation. (Brzozowski et al., 2000). On the other hand, TQ by reducing gastric oxidative injury increases bioavailability of mucosal defense systems, including GSH, SOD and NO. All these mechanisms finally maintain normal gastricmucosal barrier integrity (Zaman et al., 2004).

In conclusion, Indometacin which induces gastric ulceration can be protected with NS due to its antioxidative and anti-inflammatory enhancing properties also through inhibition of more gastric acid. The mechanism of its gastroprotective activity may be attributed to reduction in $\mathrm{pH}$, free and total acidity, ,total leukocytes ,lymphocytes and lipid peroxidation (MDA), with elevate in RBCs, HB\%, neutrophils, GSH, NO, and PGE2 on serum, blood and gastric mucosa. The presence of thymoqunione phytoconstituent in this medicinal plant particularly might be responsible for these pharmacological actions.

\section{References}

[1]. Adeniyi B. A., Oluwale, F. S. and Anyiam, F. M. (2006). Antimicrobial and antiulcer activity of methanolic extract of allium sativum on helicobacter pylori. Journal of Biological Sciences.6: (37) 521-526. 
[2]. Al-Ghamdi, M. S. (2001). The anti-inflammatory, analgesic and antipyretic activity of Nigella sativa. J. Ethnopharmacol. Jun; 76(1):45-8.

[3]. Ali, B. H. and Blunden, G. (2003). Pharmacological and Toxicological properties of Nigella sativa. Phytother. Res. 17 (4): 299 305 .

[4]. Al-Jishi, S. A. (2000). A Study of Nigclla Sativa on blood hemostatie functions. M.Sc. Thesis, King Faisal University, Dammam, Saudi Arabia.

[5]. Alkofahi, A. and Attanda, A. H. (1999). Pharmacological screening of the anti-ulcerogenic effects of some jordanian medicinal plants in rats. J. Ethnopharmacol., 67, 341-345.

[6]. Aqel, M. and Shaheen. (1996). Effects of volatile oil of Nigella sativa seeds on the uterine smooth muscle of rat and guinea pig. J Ethnopharmacol, 52, 23-26.

[7]. Bahuguna, Y., Juyal, V., and Gusain, K. (2008). Pharmacological evaluation of solanum surattenes leaves for antiulcer activity. Indian Journal of Pharmacy Research.1: (2) 253-259.

[8]. Bech, P. L., Xavier, R., Lu, N., Nanda, N. N., Dinauer, M., Podolsky, D. K. and Seed, B. (2000). Mechanisms of nsaid-induced gastrointestinal injury defined using mutant mice. Gastroenterology, 119(3):699-705.

[9]. Bhatnagar, M., Jain, C. P. and Sisodia, S. S. (2005). Antiulcer activity of withania somnifera in stress plus pyloric ligation induced gastric ulcer in rats.5: (1) 287-292.

[10]. Boesby, S., Man, W. K., Mendez-Diaz, R. and Spencer J. (1983). Effect of cysteamine on gastroduodenal mucosal histamine in the rat. Gut 24, 93 5- 939 .

[11]. Briden, S., Flemstrom, G. and Kivilaakso, E. (I985). Cysteamine and propionitrile inhibit the rise of duodenal mucosal alkaline secretion in response to luminal acid in rats. Gastroenterology 88, 295-302.

[12]. Brzozowski, T., Konturek, P. C., Konturek, S. J., Drozdowicz, D., Kwiecien, S., Pajdo, R., Bielanski, W. and Hahn, E. G. (2000). Role of gastric acid secretion in progression of acute gastric erosions induced by ischemia-reperfusion into gastric ulcers. Eur. J.Pharmacol.398, 147-158.

[13]. Bush, B. M. (1991): Interpretation of result in clinical medicine. Blackwell scinetific publication Pp. 35-40.

[14]. Chattopadhyay, I., Bandyopadhyay, U., Biswas, K., Maity, P. and Banerjee, R. K. (2006). Indomethacin inactivates gastric peroxidase to induce reactiveoxygen- mediated gastric mucosal injuty and curcumin protects it by preventing peroxidase inactivation and scavenging reactive oxygen. free radic. Biol. Med., 40(8):1397-1408.

[15]. Cheng, C. I., Koo, M. (2000). Effect of centella asiatica on ethanol induced gastric mucosal lesions in rats. Life Sci. 67: 26472653.

[16]. Ekstrom, P., Carling, L., Wtterhus, S., Wingren, P., Anker-Hansen, O. and Lundegardh, G.(2004). Prevention of peptic ulcer and dyspeptic symptoms with omeprazole in patients receiving continuous non-steroidal anti-inflammatory drug therapy. Scand J Gastroenterol; 31(8):753-8.

[17]. El-Din, K., El-Tahir, H., Bakeet, D.M. (2006).The Black Seed (Nigella Sativa Linnaeus) - A Mine for multi cures: a plea for urgent clinical evaluation of its volatile oil. Jtu. Med. Sci. 1: 1-19.

[18]. El-Missiry, M.A., El-Sayed, I. H. and Othman, A. I. (2001). Protection by metal complexes with sod mimetic activity against oxidative gastric injury induced by indomethacin and ethanol in rats. Ann Clin Biochem., 38:694-700.

[19]. Evans, W. C. (2002). Trease and Evan's Pharmacognosy. Haroourt Publishers, London, Isbn: 0702026174, P.336-337.

[20]. Feldman, M. (1998). Gastric secretion, normal and abnormal. in: feldman m, scharschmidt bf, sleisenger mh sleisenger and fordtran's gastrointestinal and liver disease: pathophysiology / diagnosis/management. $6^{\text {th }}$ Edn. wb saunders co, philadelphia, P.587603.

[21]. Fujita, H., Takahashi, S., Okabe, S. (1998). Mechanism by which indomethacin delays the healing of acetic acid-induced ulcers in rats. Role of neutrophil antichemotactic and chemotactic activities. J. Physiol. Pharmacol. 49: 71-82.

[22]. Gilman, A.G., Goodman, L. S., Rall, T. W. and Murad, F. (1985): Goodman and Gilman's the Pharmacological Basis of Therapeutics $7^{\text {th }}$ Ed. Macmillan Publishing Co. New York, Pp. 695-697.

[23]. Grossman, M. I. (1978). Control of gastric secretion in gastrointestinal disease, patho physiology- diagnosis and management. Sleisenzer, M.H, Fordtran, J.S., Editors. ${ }^{\text {nd }}$ Ed. W B Saunders Co, Philadelphia, P.640- 659.

[24]. Halter, F., Schamassman, A., Peskar, B. M. and Tarnawski, A. S. (2001). Cyclooxygenase-2 Implications on Maintenance of Gastric Mucosal Integrity and Ulcer Healing: Controversies and Perspectives. Gut 49:443-453.

[25]. Harborne, J. B. (2007). Phytochemical Methods: A Guide to Modern Techniques of Plant Analysis. Chapman and Hall, London, Isbn: 81-8128-410-4, P.1-34.

[26]. Hedaya, S. A. (1995): Effect of Nigella Sativa (Black Seeds) Extract on Some Haematological and Biochemical Parameters In Rats. Alexandria Journal of Veterinary Science 11: 95-99.

[27]. Hiruma-Lima, C. A., Calvo, T. R., Rodriguez, C.M., Andrade, F. D. P., Vilegas, W. and Brito, A. (2006). Antiulcerogenic activity of alchornea castaneaefolia: effects on somatostatin, gastrin and prostaglandin. J. Ethnopharmacol., 104(1-2):215-224.

[28]. Ikeda Y. and Kitajima M. (I985) Experimental studies on pathogenesis of duodenal ulcer in cysteamine induced rats. Dig. Dis. Sci. 30, 38i (Ai 7).

[29]. Jayatilleke, E. and Shaw, S. (1993). A High Performance Liquid Chromatographic assay for reduced and oxidized glutathione in biological samples. Anal. Biochem., 214(2): 452-457.

[30]. Karatep, M. (2004). Simulatenous determination of ascorbic acid and free malondialdehyde in human serum by HPLC-UV. Chromatographic Line. 12:362-365.

[31]. Khalife, K. H., Lupidi, G. (2007). Non Enzymatic Reduction of Thymoquinone in physiological conditions. Free Radical Res.4, $153-161$.

[32]. Kim, H., Kim, K.H., 1998. Effect of nitric oxide on hydrogen peroxide-induced damage in isolated rabbit gastric glands. Pharmacology 57, 323-330.

[33]. Kirkegaard, P., Poulsen, S. S., Loud, F. B., Halse, C., Christiansen, J. (1980) Cysteamine induced duodenal ulcer and acid secretion in the rat. Scand. J. Gastroenterol. I5, 62i-624.

[34]. Lanas, A., Bajador, E., Serrano, P., Fuentes, J., Carreňo, S., Guardia, J., Sanz, M., Montoro, M. and Sáinz, R. (2000). Nitrovasodilators, low-dose aspirin, other non-steroidal anti-inflammatory drugs, and the risk of upper gastrointestinal bleeding. N. Eng. J. Med. 343(12):834-839.

[35]. Leung, F.W., Itoh, M., Hirabayashi, K. and Guth, P. H. (I985) Role of blood flow in gastric and duodenal mucosal injury in the rat. Gastroenterology 88, 28i-289.

[36]. Li, X., Andersson, T. B., Ahlstom, M., Weidolf, L. (2004). Comparison of inhibitory effects of the proton pump-inhibiting drugs omeprazole, esomeprazole, lansoprazole, pantoprazole, and rabeprazole on human cytochrome p450 activities. Drug Metabolism and Disposition, 32(8): 821-827. 
[37]. Lüllmann, H., Mohr, K., Ziegler, A. and Bieger, D. (2000). Color atlas of pharmacology. 2nd ${ }^{\text {Ed }}$. Thieme Stuttgart, New York, P.166.

[38]. Makinde, A.J. (1991): The Toxic Effect of Varying Doses of Indometacin on the Laboratory Rodents. Dvm Dissertation, University of Ibadan (Unpublished).

[39]. Mandour, A., Mahmoud, K., Abou El-Wafa, A., El- Agamy, E. and Ragab, O. (1998). Effect of Aflatoxin and Nigella Sativa Seeds on Serum Proteins and Its Electrophoretic Patterns in White Pekin Ducklings. $1^{\text {st }}$ Egyptian Hungarian Poultry Conference, Alexandria, Egypt.

[40]. Mansour, M. A., Nagi, M. N., El-Khatib, A. S., Al-Bekairi, A. M., (2002). Effects of Thymoquinone on Antioxidant Enzyme Activities, Lipid Peroxidation and Dt- Diaphorase in Different Tissues of Mice: A Possible Mechanism of Action. J. Cell Biochem. Funct.20, 143-151.

[41]. Miller, T. (1983). Protective Effects of Prostaglandins against Gastric Mucosal Damage: Current Knowledge and Proposed Mechanisms. Am. J. Physiol., 346(8974):521-522.

[42]. Moore, E. W. (1968). Determination of Ph by the Glass Electrode: Ph Meter Calibration for Gastric Analysis. Gastroenterology, 54(4):501-507.

[43]. Muralidhran, P. and Srikanth J. Antiulcer Activity of Morinda Citrifolia Linn Fruit Extract. J. Sci. Res. 2011; 1: (2) 345-352.

[44]. Nagaya, H., Inatomi, N., Ohara, A. and Satoh, H. (1991). Effects of the Enantiomers of Lansoprazole (Ag-1749) on (H++ K+)Atpase activity in canine gastric microsomes and acid formation in isolated canine parietal cells. Biochemical Pharmacology, 42(10): 1875-1878.

[45]. Okabe, S., Pfeiffer, C. J. and Roth, J. l. (1997): Experimental Production of Duodenal and Antral Ulcers in Rats. Federal Proc 29: 255

[46]. Pal, S., Choudhuri, T., Chattopadhyay, S., Bhattacharya, A., Datta, G. K., Das, T. and Sa, G. (2001). Mechanisms of curcumin induced apoptosis of Ehrlich's ascites carcinoma cells. Biochem. Biophys. Res. Commun. 288: 658-665

[47]. Papadoyannis, L. N., Samanidou, V. F. and Nitsos, Ch. C. (1999). Simultaneous determination of nitrite and nitrate in drinking water and human serum by high performance anion-exchange chromatography and UV detection. J. Liq. Chrom. Rel. Technol., 22(13): 2023 - 2041 .

[48]. Pratt, D. E. (1992). Natural antioxidants from plant Material. In: Huang, I.M.T., Ho, C.T., Lee, C.Y., Editors. Phenolic Compounds in Food and Their Effects on Health. New York: American Chemical Society, P.54-72.

[49]. Pugh, S., Williams, S. E., Lewin, M. R., Ishaqije, M., Barton, T. P., Bose, K., Bardhan, K. D. and Clark, C. G. (I989). Duodenal and antral mucosal prostaglandin E2 synthesis in a study of duodenal ulcer disease treated by $\mathrm{H} 2$ receptor antagonists. Gut 30, I6i-I65.

[50]. Rainsford, K. D. D. (1987). The Effects of 5- Lipoxygenase Inhibitors and Leukotriene antagonists on the Development of Gastric Lesions Induced by Bush, B. M. (1991): Interpretation of Result in Clinical Medicine. Blackwell Scinetific Publication Pp. 35-40.

[51]. Ramadan, M. f. (2007). Nutritional Value, Functional Properties and Nutraceutical Applications of Black Cumin (Nigella Sativa L.): An Overview. Int. J. Food. Sci. Tech. 42 (10): 1208-1218.

[52]. Rates, S. M. K. (2001). Plants as Source of Drugs. Toxicon, 39(5): 603-613.

[53]. Repetto, M. G.; Llesuy, S. F. (2002). Antioxidant Properties of Natural Compounds Used In Popular Medicine For Gastric Ulcers. Braz. J. Med. Biol. Res.35, 523-534.

[54]. SAS. Statistical Analysis Systems Institute (1989). SAS/STAT user's guide: release 6.03. SAS institute Inc., Cary, NC. USA.

[55]. Satoh, H., Inatomi, N., Nagaya, H., Ianda, I., Nohara, A., Nakamura, H. (1989). antisecretory and antiulcer Activities of A Novel Proton Pump Inhibitor Ag-1749 in Dogs and Rats. Journal of Pharmacology and Experimental Therapeutics, 1989, 248(2): 806-815

[56]. Schalm, O. W. Jain, N. C. and Caroll, E. J. (1975). Veterinary haematology 3rd Ed. Lea and Febiger Philadelphia Pp. 602- 630

[57]. Schmeda-Hirschmann, G. and Yesilada, E. (2005). Traditional Medicine and Gastroprotective Crude Drugs. J. Ethnopharmacol., 100(1-2):61-66.

[58]. Shiina, Y., Kikuchi, K., Harasawa, S., Matsumoto, M. and Miwa, T. (1985). Changes of the Duodenogastric Glycoproteins during Cysteamine Induced Ulcer Formation. Dig. Dis. Sci. 30, 401 (A3 7).

[59]. Shimizu, N., Watanabe, T., Arakawa, T., Fujiwara, Y., Higuchi, K. and Kuroki, T. (2000). Pentoxifylline Accelerates Gastric Ulcer Healing In Rats: Roles of Tumor Necrosis Factor Alpha and Neutrophils During The Early Phase of Ulcer Healing. Digestion 6: 157-164.

[60]. Su, G. L., Goyert, S. M., Fan, M. H., Aminlari, A., Gong, K. Q., Myc, A., Alarcon, W. H., Steinstraesser, L., Remick, D. G. and Wang, S. C. (2002). Activation of Human and Mouse Kupffer Cells By Lipopolysaccharide Is Mediated By Cd14. Am. J. Physiol. Gastrointest. Liver Physiol., 283(3):G640- G645.

[61]. Suzuki, Y., Ishihara, M. and Ito, M. (1998). Anti-Ulcer Effects of Antioxidants, Quercetin, $\alpha$-Tocopherol, Nifedipine and Tetracycline in Rats. Japanese J. Pharmacol. 78: 435-441

[62]. Tanaka, J., Yuda, Y., Inouye, S. and Yamakawa, T. (2001). The Role of Nitric Oxide in the Gastric Acid Secretion Induced By Ischemia-Reperfusion in the Pylorus-Ligated Rat. Eur. J. Pharmacol. 424, 69-74.

[63]. Tennekoon, K. H., Jeevathayaparan, S., Kurukulasooriya A. P. and Karunanayake, E. H. (1991). Possible Hepatotoxicity of Nigella Sativa Seeds and Dregea Volubilis Leaves. J. Ethnopharmacol. 31: 283-289.

[64]. Tripathi, K. D. (1999). Essentials of Medical Pharmacology. Jaypee Brothers Medical Publishers (P) Ltd. New Delhi, 1999, Pp. 628- 642

[65]. Tripp, M. A. and Tepperman, B. L. (1995). Effect of Nitric Oxide on Integrity, Blood Flow and Cyclic Gmp Levels in the Rat Gastric Mucosa: Modulation by Sialoadenectomy. Br. J. Pharmacol., 115(2):344-348.

[66]. Wallace, J. L. and Granger, D. N. (1996). The Cellular and Molecular Basis of Gastric Mucosal Defense. Faseb J., 10(7):731-740.

[67]. Whittle, B. J. R., Higgs, G. A., Eakins, K. E., Moncada, S. and Vane, J. R. (1990). Selective Inhibition of Prostaglandin Production in Inflammatory Exudates and Gastric Mucosa. Nature 284:271

[68]. Zaman, R., Akhtar, M. S. and Khan, M. S. (2004). Gastroprotective and Antisecretary Effect of Nigella Sativa Seed and Its Extracts In Indomethacin-Treated Rats. Pak J Biol Sci. 7:995-1000.

[69]. Zaoui, A., Cherrah, Y., Alaoui, K., Mahassine, N., Amarouch, H. and Hassar, M. (2002). Effect of Nigella Sativa fixed oil on Blood Homeostasis in Rat. J. Ethnopharmacol. 79: 23-26.

[70]. Zimmerman, J. J., Ciesielski, W. and Lewandoski, J. (1997). Neutrophilmediated phospholipids peroxidation assessed by gas chromatography-Mass spectroscopy. Am. J. Physiol. 273: 653-661. 